NBER WORKING PAPER SERIES

\title{
ASSET PRICING IMPLICATIONS OF MACROECONOMIC INTERVENTIONS AN APPLICATION TO CLIMATE POLICY
}

\author{
Rajnish Mehra \\ Working Paper 19146 \\ http://www.nber.org/papers/w19146 \\ NATIONAL BUREAU OF ECONOMIC RESEARCH \\ 1050 Massachusetts Avenue \\ Cambridge, MA 02138 \\ June 2013
}

I thank Stephen DeCanio, George Constantinides, John Donaldson, Bob Litterman, Robert Pindyck and Edward Prescott for invaluable feedback and comments. I also thank the participants of the conference on Pricing Climate Risk: Refocusing the Climate Policy Debate at ASU for their comments and Yan Chen for his research assistance. The usual caveat applies. The views expressed herein are those of the author and do not necessarily reflect the views of the National Bureau of Economic Research.

NBER working papers are circulated for discussion and comment purposes. They have not been peerreviewed or been subject to the review by the NBER Board of Directors that accompanies official NBER publications.

(C) 2013 by Rajnish Mehra. All rights reserved. Short sections of text, not to exceed two paragraphs, may be quoted without explicit permission provided that full credit, including $(\mathbb{C}$ notice, is given to the source. 
Asset Pricing Implications of Macroeconomic Interventions

An Application to Climate Policy

Rajnish Mehra

NBER Working Paper No. 19146

June 2013

JEL No. E44,E6,G00,G12,G31,H00,O1,Q54

\begin{abstract}
$\underline{\text { ABSTRACT }}$
This paper illustrates that evaluating alternate abatement polices that affect the growth path of an economy on the basis of their effects on asset valuation may not be welfare enhancing. We show that the class of abatement polices considered in the integrated assessment literature are robust with respect to the choice of a discount factor if lifetime consumption equivalents are used as a metric. We argue against a global welfare function in the presence of significant global household heterogeneity. While economic analysis is a useful tool for evaluating different policies for a homogenous class of households, inter household comparisons are an ethical issue.
\end{abstract}

Rajnish Mehra

Department of Economics

W. P. Carey School of Business

Arizona State University

PO Box 879801

Tempe, AZ 85287-9801

and NBER

rajnish.mehra@asu.edu 


\section{Introduction}

We characterize macroeconomic interventions as interventions that change the growth path of an economy. The interventions may be due to natural causes such as the "Black Death" in the fourteenth century or the last ice age or they may be man made, such as the Great Wars in the twentieth century.

Anthropogenic climate change is an issue that has come to dominate the global public policy agenda. It is argued that if left unchecked, the accumulation of greenhouse gases in the atmosphere will negatively impact future per capita consumption. At the heart of the debate is evaluating alternative policies for greenhouse gas abatement. An abatement policy reduces current per capita consumption in exchange for a higher growth rate in the future. The default option of no intervention results in higher per capita current consumption but a lower future growth rate.

This paper illustrates that evaluating alternate abatement polices that affect the growth path of an economy based on their impact on asset valuation ${ }^{1}$ may not be a good measure of the welfare consequences of the policies ${ }^{2}$.

The framework used for evaluating alternative policies in the climate modeling literature, the various integrated assessment models, are an extension of neoclassical growth theory. Asset pricing in this context has been studied in Prescott and Mehra (1980), Brock (1982) and Donaldson and Mehra (1984). An insight that simplifies the analysis is the observation that the cross equation restrictions on asset prices and consumption do not depend on whether the consumption process is endogenously determined, as in an economy with

\footnotetext{
1 For a discussion of the impact of climate change on asset valuation see Ahlroth (2009) and Hanewinkel (2013) and the references in these papers

${ }^{2}$ See Jensen and Long (1972) and the Symposium on the Optimality of Capital Markets in the The Bell Journal of Economics and Management Science Spring, 1974, especially Merton and Subrahmanyam (1974) for a related observation in the context of the CAPM.
} 
production or is exogenous as in an exchange economy ${ }^{3}$. The relative prices of the date, event-contingent, composite-consumption goods are proportional to the marginal rates of substitution of consumption. The deus ex machina of this class of asset pricing models is that for a given endowment process, household trading of financial assets is motivated by a desire to smooth consumption, both over time and across states at a point in time. The desirability of an asset in this model reflects its ability to smooth consumption. Hence, assets that pay off in future states when consumption levels are high - when the marginal utility of consumption is low - are therefore less desirable than those that pay an equivalent amount in future states when consumption levels are low and additional consumption is more highly valued ${ }^{4}$. As a consequence, the price of a claim to a unit of consumption at some future time t scales in proportion to the marginal utility of consumption at that time. Both the household's elasticity of intertemporal substitution and risk aversion play a crucial role in this class of models.

In these models, the price of an asset at time $\mathrm{t}, p_{t}$ with stochastic payoffs $\left\{y_{s}\right\}_{s=t+1}^{\infty}$ is

$$
p_{t}=E\left[\sum_{s=t+1}^{\infty} m_{s, t} y_{s} \mid \Phi_{t}\right]
$$

where $\left\{m_{s, t}\right\}_{s=t+1}^{\infty}$ a stochastic process ${ }^{5}, \Phi_{t}$ is the information available to households who trade assets at time $\mathrm{t}$ and $E$ is the expectations operator. $m_{s, t}$ is

\footnotetext{
${ }^{3}$ In a production economy the class of consumption processes will be a subset of the processes in an exchange economy. See Mehra and Prescott (2008) Appendix C.

${ }^{4}$ Consumption levels are relative to current consumption.

${ }^{5} m_{s, t}=\prod_{k=0}^{s-t-1} m_{t+k+1, t+k}$, where $m_{t+k+1, t+k}$ is a random variable such that

$p_{t+k}=E\left[m_{t+k+1, t+k} y_{t+k+1} \mid \Phi_{t+k}\right]$.
} 
usually expressed as a function of the marginal rate of substitution of consumption between time $s$ and $t$ of the agents who trade securities. For example, in a widely cited and influential paper, Lucas (1978) models $m_{s, t}$ as $\beta^{s-t} u^{\prime}\left(c_{s}\right) / u^{\prime}\left(c_{t}\right)$. Here $c_{t}$ is the aggregate per capita consumption at time $t, u^{\prime}\left(c_{t}\right)$ is the marginal utility of consumption at time $t$ and $\beta$ is the rate of time preference. In the case of isoelastic utility, $m_{s, t}$ specializes to $\beta^{s-t}\left(c_{s} / c_{t}\right)^{-\alpha}$, where $\alpha$ is the coefficient of relative risk aversion and, simultaneously, the reciprocal of the elasticity of intertemporal substitution.

In this model class, Mehra and Prescott (1985) find that the premium for bearing non-diversifiable aggregate risk is small. This premium ${ }^{6}$ is approximately equal to $\alpha \sigma_{c}^{2}$ where $\sigma_{c}^{2}$ is the variance of the growth rate of consumption. For the U.S. the historical average for $\sigma_{c}^{2}$ is 0.0018. Since plausible values of $\alpha$ are upper bounded by 10, we will abstract from this small premium and consider an economy with no aggregate uncertainty. Uncertainty is not essential to the point we establish and this abstraction simplifies the analysis ${ }^{7}$.

The point of departure of this paper is the observation that any major intervention in the economy, such as climate abatement policies that affect the consumption process, will change the stochastic process $\left\{m_{s, t}\right\}_{s=t+1}^{\infty}$ thereby changing prices relative to current consumption of all assets in the economy. The intuition is straightforward. A reduction in the growth of an economy, will in steady state, have two effects. It will reduce future consumption ${ }^{8}$ and it will lead to a reduction in the equilibrium interest rate. The first effect tends to reduce the relative value of assets while the second increases the value of the assets relative

\footnotetext{
${ }^{6}$ It is exact if the growth rate of consumption is i.i.d and log-normally distributed.

${ }^{7}$ The issues involved in the treatment of uncertainty, including uncertainties about the magnitude, timing, and impacts of climate change, are discussed in Howarth (2003), Weitzman (2007, 2009) and Ackerman et al. (2009).

${ }^{8}$ Relative to an economy with no reduction in its growth rate.
} 
to current consumption. The net result is ambiguous. We illustrate this in section 2 with a simple example.

The paper consists of 5 sections. In section 3 we evaluate a stylized abatement policy based on two measures: asset valuation and household welfare, measured in lifetime consumption equivalents and show that these lead to inconsistent rankings. In section 4 we address heterogeneity in preferences and issues of aggregation. Section 5 concludes the paper.

\section{An Illustrative Example}

Consider a certainty analog of an endowment economy of the type analyzed in Mehra and Prescott (1985). There is a single infinitely lived household with isoelastic preferences. This unit orders its preferences over consumption paths by

$$
\sum_{t=0}^{\infty} \beta^{t} \frac{c_{t}^{1-\alpha}-1}{1-\alpha}, \quad 0<\beta<1,0<\alpha<\infty
$$

where $c_{t}$ is the per capita consumption.

The parameter $\beta$ is the rate of time preference, which describes how impatient households are to consume. If $\beta$ is small, people are highly impatient, with a strong preference for consumption now versus consumption in the future. The parameter $\alpha$ measures the curvature of the utility function. When $\alpha=1$, the utility function is defined to be logarithmic, which is the limit of the above representation as $\alpha$ approaches 1 .

As modeled, the household lives forever, which implicitly means that the utility of parents depends on the utility of their children ${ }^{9}$.

\footnotetext{
${ }^{9}$ See Becker and Barro (1988)
} 
Land is the only asset in this economy. Its ownership entitles the owner to the entire consumption stream $\left\{c_{s}\right\}_{s=t+1}^{\infty}$. The price of land at time $\mathrm{t}, p_{t}$ is ${ }^{10}$ :

$$
p_{t}=\sum_{s=t+1}^{\infty} \beta^{s-t}\left(c_{s} / c_{t}\right)^{-\alpha} c_{s}
$$

The discount factor is the sequence $\left\{m_{s, t}\right\}_{s=t+1}^{\infty}$ with $m_{s, t}=\beta^{s-t}\left(c_{s} / c_{t}\right)^{-\alpha}$.

Consider two such economies, identical in every respect expect that land in one economy produces the consumption good with a growth rate of $2 \%$ while in the other the growth rate is $1 \%$. The household elasticity of intertemporal substitution is $0.5(\alpha=2)$ and its $\beta=0.99$. Consumption levels are 1 in both economies at time 1.

Let $p_{0}^{h}$ and $p_{0}^{l}$ be the price of land in the high growth and the low growth economies respectively at time 0 . Using the pricing relation above, it is straightforward to find relative valuation of the land in the two economies in today's consumption equivalent.

$$
p_{0}^{h} / p_{0}^{l}=\frac{\left(1+g^{l}\right)^{\alpha-1}-\beta}{\left(1+g^{h}\right)^{\alpha-1}-\beta}
$$

For an economy characterized by the above parameters we find that $p_{0}^{h} / p_{0}^{l}=2 / 3$ even though the household welfare is higher in the higher growth economy irrespective of $\alpha$. The reason for this counter - intuitive result is that, as mentioned earlier, the discount rate is a function of the growth rate of

\footnotetext{
${ }^{10}$ See equation (6) in Mehra and Prescott (1985). As shown in Mehra (1988), equilibrium in this economy can exist even if $\beta>1$. Equilibrium will exist if $\beta<(1+g)^{\alpha-1}$. We assume that this condition holds in this paper.
} 
consumption and is different in the two economies. The discount rate is given $\mathrm{by}^{11}$ :

$$
r=-\ln \beta+\alpha \mu_{c}
$$

where $\mu_{c}=\ln (1+g)$ is the continuously compounded growth rate of consumption. For the U.S, over the past 100 years the growth rate of consumption has averaged slightly less than $2 \%$. With $\alpha=2$, in the high growth economy the discount rate is $5 \%$ while in the low growth economy it is $3 \%$. In the low growth economy the increase in the value of land due to the lower discount rate more than offsets the reduction due to the decrease in consumption. In the case when household $\alpha$ is 1 (logarithmic preferences) $p_{0}^{h} / p_{0}^{l}=1$, as the two effects exactly offset each other.

Table 1 reports the value of $p_{0}^{h} / p_{0}^{l}$ and confirms this observation for a wide range of values of $\alpha$ and $\beta$.

This simple example illustrates that evaluating polices that affect aggregate consumption based on their impact on asset values may not be a good measure of the welfare consequences of the policies.

\footnotetext{
${ }^{11}$ See equation 18 in Mehra (2012). Note that we are assuming no uncertainty, hence $\sigma_{c}^{2}=0$. Tol (1994) discusses the case when $\mu_{c}$ is negative.
} 


\section{Table 1}

Values for $p_{0}^{h} / p_{0}^{l}$ implied by $\alpha$ and $\beta$

\begin{tabular}{|c|c|c|c|c|c|c|}
\hline$\alpha$ & $\beta$ & 0.97 & 0.98 & 0.99 & 1.0 & 1.01 \\
\hline 0.5 & & 1.24 & 1.48 & 34.15 & N.A & N.A \\
\hline 1 & & 1 & 1 & 1 & N.A & N.A \\
\hline 2 & & 0.80 & 0.75 & 0.67 & 0.50 & 0 \\
\hline 3 & & 0.71 & 0.66 & 0.60 & 0.50 & 0.33 \\
\hline
\end{tabular}

N.A: Equilibrium does not exist.

\section{Evaluation of an GHG Abatement Policy}

In this section, we evaluate a stylized abatement policy based on two distinct measures: asset valuation and household welfare. We remind the reader that in the integrated assessment models of the type analyzed by Stern (2007 and 2008) and Nordhaus (2008), the welfare consequences and asset valuations depend only on the endogenous consumption process. The policy analyzed below can be considered as a "reduced form" of an integrated assessment model with an equivalent consumption process. The parameters we consider encompass a wide variety of current policy recommendations. Pindyck $(2011,2012)$ has forcefully argued that abatement policies should be modeled as effecting the growth rate of consumption rather than its level. This paper endorses this perspective and expands on it.

We evaluate two alternative policies in an economy of the type analyzed in Section 2 above:

a) No abatement or intervention: in this scenario, per capita consumption initially grows at the historical average rate of $2 \%$ for 
$T$ years. Thereafter, due to the effects of greenhouse gas emissions, the growth rate slows down to $1 \%$ and remains at that level in perpetuity $^{12}$. The reasons for this slow-down cited in the literature include: conflicts, pandemics, large scale flooding and the consequent migration of a vast number of people.

b) An abatement policy, which requires investment in carbon abatement technologies for $T$ years, resulting in a reduction in current per capita consumption by $x \%$ per year during the investment period. This investment is in addition to the normal investment required for a $2 \%$ growth (in the absence of GHG emissions). However, as a result of the abatement the growth rate remains constant at $2 \%$ indefinitely.

Figure 1 illustrates the per capita consumption path over time in the two cases.

${ }^{12}$ The results will not change if instead of a reduction in perpetuity, the reduction was for, say, 100 - 150 years. The present value of a long annuity is well approximated by a perpetuity for the discount rates considered in Table 2. 


\section{Figure 1}
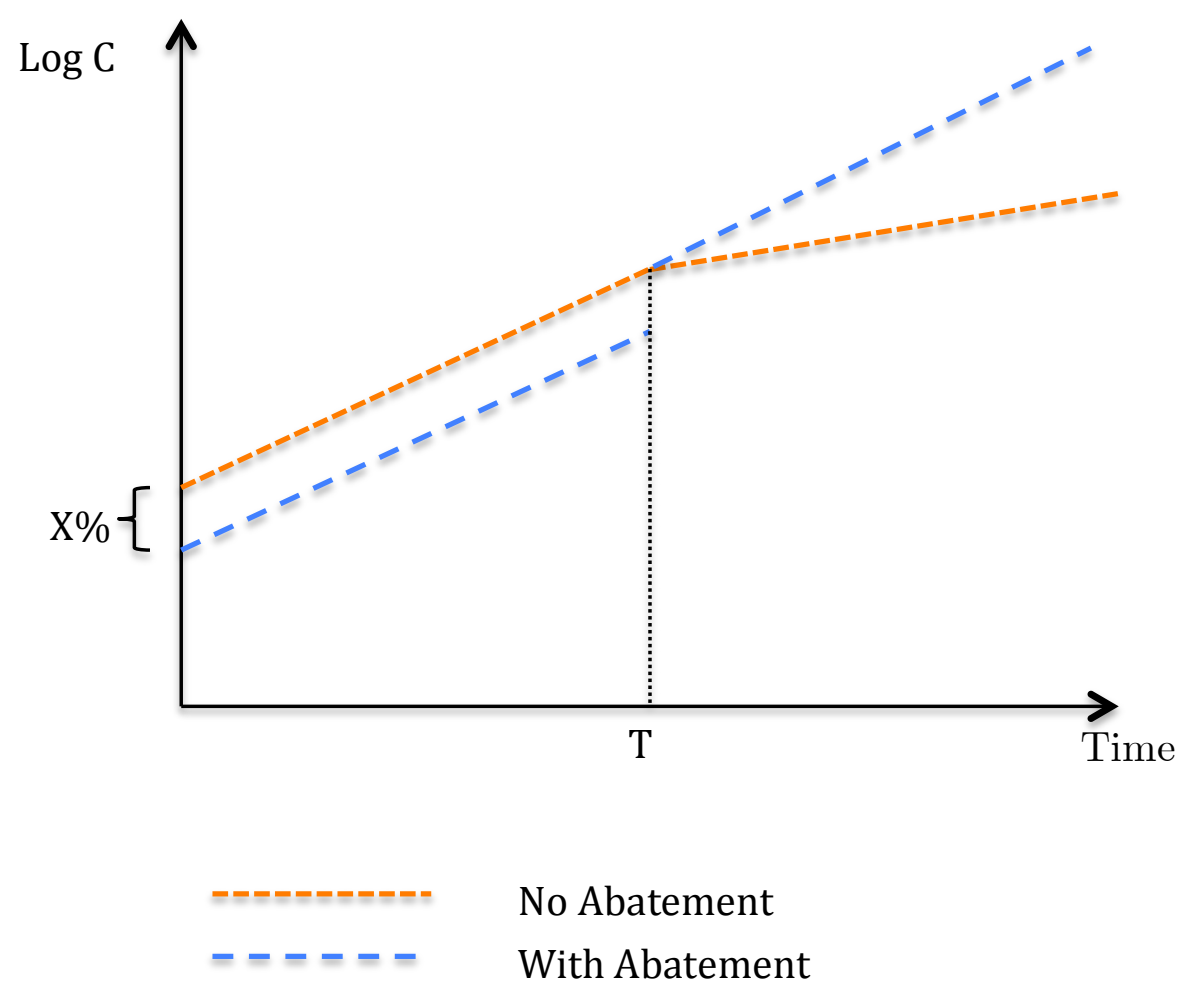

We compute the present value of land and the lifetime consumption equivalents (defined below) with and without abatement for a range of the parameters $\alpha, \beta$, and $g$. As shown in Table 2 these parameter values encompass a wide range of discount rates $r$ defined in equation 5 . 
We reiterate that the land entitles the owner to the entire future consumption stream $\left\{c_{s}\right\}_{s=t+1}^{\infty}$ and hence its price is equal to the present value of this consumption stream, valued at the endogenous interest rate. To compute the present value of land with no abatement, $p_{0}^{n a}$, we modify equation 2 to account for the decrease in growth rate after time $T$.

$$
p_{0}^{n a}=\sum_{t=1}^{T} \beta^{t}\left(c_{t}^{h} / c_{0}\right)^{-\alpha} c_{t}^{h}+\sum_{t=T+1}^{\infty} \beta^{t}\left(c_{t}^{l} / c_{0}\right)^{-\alpha} c_{t}^{l}
$$

where

$$
\begin{gathered}
c_{t}^{h}=c_{0}\left(1+g^{h}\right)^{t} \quad 1 \leq t \leq T \\
c_{t}^{l}=c_{0}\left(1+g^{h}\right)^{T}\left(1+g^{l}\right)^{t-T} \quad T+1 \leq t
\end{gathered}
$$

To compute the present value the land under abatement $p_{0}^{w a}$ we use

$$
p_{0}^{w a}=\sum_{t=1}^{T} \beta^{t}\left(c_{t}^{h} / c_{0}\right)^{-\alpha} c_{t}^{h}(1-x)+\sum_{t=T+1}^{\infty} \beta^{t}\left(c_{t}^{h} / c_{0}\right)^{-\alpha} c_{t}^{h}
$$

where

$$
c_{t}^{h}=c_{0}\left(1+g^{h}\right)^{t} \quad 1 \leq t
$$

Tables 3, 4, 5 and 6 first report the values of $p_{0}^{a} / p_{0}^{w a}$ for a range of the parameters $\alpha \in\{1,2,3\}, \beta \in\{0.98,0.99,0.999,1.01\}, x \in\{1 \%, 2 \%, 3 \%\}{ }^{13}$ and $T \in\{50,100,150, \infty\}$ (the case $T=\infty$ serves as a consistency check).

While utility is a monotonic transformation of consumption, this transformation is usually nonlinear. The present value of consumption is not the same as the present value of lifetime utility and in general, is not the correct measure of welfare.

While the various integrated assessment models do base their calculations

13 These values of $x$ cover the range of estimates of the investment effort that would be required to de-carbonize the global energy system. See DeCanio and Fremstad (2011). 
on the maximization of lifetime utility, abatement and non-abatement in these models effect the levels rather than the growth rates of consumption as in our analysis. This explains why our conclusions are different from these models.

To calculate the welfare impact of the different polices, we compute the lifetime consumption equivalents ${ }^{14}$ as in Lucas (1987). Using the no abatement policy as the base, this is the fraction of consumption that would make a household indifferent between the two policies.

Define lifetime utility with no abatement $U_{0}^{n a}$ as:

$$
U_{0}^{n a}=\sum_{t=1}^{T} \beta^{t} \frac{\left(c_{t}^{h}\right)^{1-\alpha}-1}{1-\alpha}+\sum_{t=T+1}^{\infty} \beta^{t} \frac{\left(c_{t}^{l}\right)^{1-\alpha}-1}{1-\alpha}
$$

where

$$
\begin{gathered}
c_{t}^{h}=c_{0}\left(1+g^{h}\right)^{t} \quad 1 \leq t \leq T \\
c_{t}^{l}=c_{0}\left(1+g^{h}\right)^{T}\left(1+g^{l}\right)^{t-T} \quad T+1 \leq t
\end{gathered}
$$

and compensated lifetime utility with abatement $U_{0}^{w a}(\lambda)$ as:

$$
U_{0}^{w a}(\lambda)=\sum_{t=1}^{T} \beta^{t} \frac{\left(c_{t}^{h}(1-x)(1+\lambda)\right)^{1-\alpha}-1}{1-\alpha}+\sum_{t=T+1}^{\infty} \beta^{t} \frac{\left(c_{t}^{h}(1+\lambda)\right)^{1-\alpha}-1}{1-\alpha}
$$

where

$$
c_{t}^{h}=c_{0}\left(1+g^{h}\right)^{t} \quad 1 \leq t
$$

\footnotetext{
14 The astute reader would have noticed that we cannot take the ratio of lifetime utility of consumption to evaluate policies. For instance a utility of $-30>-50$ but $3 / 5$ is less than 1 . Nor is the magnitude of the differences in utility an indicator of a quantitative welfare improvement, as utility functions can be arbitrarily scaled without changing the preference orderings. Computing lifetime consumption equivalents makes it possible to make quantitative assessments for a homogenous class of households.
} 
If we equate $U_{0}^{w a}(\lambda)$ to $U_{0}^{n a}$ and solve for $\lambda$, we get the fraction by which consumption under abatement must be increased or decreased to make the household indifferent to the no abatement policy.

Tables 3, 4, 5 and 6 report the values of $\lambda$ for a range of the parameters $\alpha \in\{1,2,3\}, \beta \in\{0.98,0.99,0.999,1.01\}, x \in\{1 \%, 2 \%, 3 \%\}$ and $T \in\{50,100,150, \infty\}$.

\section{Table 2}

Values for $r(\%)$ implied by $\alpha$ and $\beta$ when $g=2 \%$

\begin{tabular}{cccccc}
\hline & $\beta$ & $\mathbf{0 . 9 8}$ & $\mathbf{0 . 9 9}$ & $\mathbf{0 . 9 9 9}$ & $\mathbf{1 . 0 1}$ \\
\cline { 2 - 5 } $\mathbf{1}$ & $\mathbf{4}$ & $\mathbf{3}$ & 2 & N.A \\
$\mathbf{2}$ & $\mathbf{6}$ & 5 & $\mathbf{4}$ & 3 \\
$\mathbf{3}$ & 8 & 7 & 6 & $\mathbf{5}$
\end{tabular}

N.A: Equilibrium does not exist.

Values of $r$ implied by $\alpha$ and $\beta$ in Tables 3, 4 5, 6 and 7 are in bold

Values for $r(\%)$ implied by $\alpha$ and $\beta$ when $g=1 \%$

\begin{tabular}{cccccc}
\hline & $\beta$ & $\mathbf{0 . 9 8}$ & $\mathbf{0 . 9 9}$ & $\mathbf{0 . 9 9 9}$ & $\mathbf{1 . 0 1}$ \\
\cline { 2 - 5 } $\mathbf{1}$ & $\mathbf{3}$ & $\mathbf{2}$ & 1 & N.A \\
$\mathbf{2}$ & $\mathbf{4}$ & 3 & $\mathbf{2}$ & 1 \\
$\mathbf{3}$ & 5 & 4 & 3 & $\mathbf{2}$
\end{tabular}

N.A: Equilibrium does not exist.

Values of $r$ implied by $\alpha$ and $\beta$ in Tables 3, 4 5, 6 and 7 are in bold 
Table 3

PV with abatement/PV with no abatement $p_{0}^{w a} / p_{0}^{n a}$

$$
\alpha=1, \beta=0.98
$$

\begin{tabular}{ccccc}
\hline & \multirow{2}{*}{$x \%$} & 1 & 2 & 3 \\
\cline { 1 - 3 } 50 & & 0.994 & 0.987 & 0.981 \\
\cline { 3 - 5 } 100 & & 0.991 & 0.983 & 0.974 \\
150 & & 0.990 & 0.981 & 0.971 \\
$\infty$ & & 0.990 & 0.980 & 0.970 \\
\hline
\end{tabular}

Lifetime consumption equivalent $\lambda$

$$
\alpha=1, \beta=0.98
$$

\begin{tabular}{ccccc}
\hline & \multirow{2}{*}{$x \%$} & 1 & 2 & 3 \\
\cline { 4 - 5 } 50 & & -0.159 & -0.153 & -0.148 \\
100 & & -0.055 & -0.047 & -0.038 \\
150 & & -0.014 & -0.005 & 0.005 \\
$\infty$ & & 0.010 & 0.020 & 0.031 \\
\hline
\end{tabular}




\section{Table 4}

PV with abatement/PV with no abatement $p_{0}^{w a} / p_{0}^{n a}$ $\alpha=2, \beta=0.98$

\begin{tabular}{ccccc}
\hline \multirow{2}{*}{$T$} & $x \%$ & 1 & 2 & 3 \\
\cline { 1 - 3 } 50 & & 0.949 & 0.940 & 0.932 \\
\cline { 3 - 5 } 100 & & 0.984 & 0.974 & 0.964 \\
150 & & 0.989 & 0.979 & 0.969 \\
$\infty$ & & 0.990 & 0.980 & 0.970 \\
\hline
\end{tabular}

Lifetime consumption equivalent $\lambda$

$$
\alpha=2, \beta=0.98
$$

\begin{tabular}{ccccc}
\hline & \multirow{2}{*}{$x \%$} & 1 & 2 & 3 \\
\cline { 4 - 5 } 50 & & -0.034 & -0.024 & -0.014 \\
100 & & 0.004 & 0.014 & 0.025 \\
150 & & 0.009 & 0.020 & 0.030 \\
$\infty$ & & 0.010 & 0.020 & 0.031 \\
\hline
\end{tabular}




\section{Table 5}

PV with abatement/PV with no abatement $p_{0}^{w a} / p_{0}^{n a}$ $\alpha=1, \beta=0.99$

\begin{tabular}{ccccc}
\hline \multirow{2}{*}{$T$} & $x \%$ & 1 & 2 & 3 \\
\cline { 1 - 3 } 50 & & 0.995 & 0.991 & 0.986 \\
\cline { 3 - 5 } 100 & & 0.993 & 0.987 & 0.981 \\
150 & & 0.992 & 0.984 & 0.976 \\
$\infty$ & & 0.990 & 0.980 & 0.970 \\
\hline
\end{tabular}

Lifetime consumption equivalent $\lambda$

$$
\alpha=1, \beta=0.99
$$

\begin{tabular}{ccccc}
\hline \multirow{2}{*}{$T$} & $x \%$ & 1 & 2 & 3 \\
\cline { 4 - 5 } 50 & & -0.447 & -0.445 & -0.442 \\
100 & & -0.298 & -0.294 & -0.289 \\
150 & & -0.190 & -0.183 & -0.177 \\
$\infty$ & & 0.010 & 0.020 & 0.031 \\
\hline
\end{tabular}




\section{Table 6}

PV with abatement/PV with no abatement $p_{0}^{w a} / p_{0}^{n a}$

$$
\alpha=2, \beta=0.999
$$

\begin{tabular}{ccccc}
\hline \multirow{2}{*}{$T$} & $x \%$ & 1 & 2 & 3 \\
\cline { 4 - 5 } 50 & & 0.752 & 0.747 & 0.742 \\
\cline { 3 - 5 } 100 & & 0.890 & 0.882 & 0.874 \\
150 & & 0.952 & 0.943 & 0.934 \\
$\infty$ & & 0.990 & 0.980 & 0.970 \\
\hline
\end{tabular}

Lifetime consumption equivalent $\lambda$

$$
\alpha=2, \beta=0.999
$$

\begin{tabular}{ccccc}
\hline & \multirow{2}{*}{$x \%$} & 1 & 2 & 3 \\
\cline { 4 - 5 } 50 & & -0.236 & -0.228 & -0.220 \\
100 & & -0.093 & -0.084 & -0.074 \\
150 & & -0.029 & -0.019 & -0.009 \\
$\infty$ & & 0.010 & 0.020 & 0.031 \\
\hline
\end{tabular}




\section{Table 7}

PV with abatement/PV with no abatement $p_{0}^{w a} / p_{0}^{n a}$

$\alpha=3, \beta=1.01$

\begin{tabular}{ccccc}
\hline \multirow{2}{*}{$T$} & $x \%$ & 1 & 2 & 3 \\
\cline { 1 - 3 } 50 & & 0.681 & 0.670 & 0.670 \\
\cline { 3 - 5 } 100 & & 0.897 & 0.889 & 0.880 \\
150 & & 0.967 & 0.958 & 0.948 \\
$\infty$ & & 0.990 & 0.980 & 0.970 \\
\hline
\end{tabular}

Lifetime consumption equivalent $\lambda$

$\alpha=3, \beta=1.01$

\begin{tabular}{ccccc}
\hline \multirow{2}{*}{$T$} & $x \%$ & 1 & 2 & 3 \\
\cline { 4 - 5 } 50 & & -0.163 & -0.154 & -0.146 \\
100 & & -0.039 & -0.029 & -0.019 \\
150 & & -0.002 & 0.009 & 0.019 \\
$\infty$ & & 0.010 & 0.020 & 0.031 \\
\hline
\end{tabular}


For the values of the parameters $\alpha$ and $\beta$ considered in tables $3,4,5,6$ and 7 , if $T=50$ years, a policy maker would not choose the abatement policy based on market valuation even though it is welfare enhancing in each instance. The lifetime consumption equivalents are negative. Households are willing to sacrifice consumption, in addition to that required by the abatement policy, to avoid a reduction in future growth rates.

A striking result of this analysis is that the policy recommendations are robust across a wide range of discount rates ranging from $3 \%$ to $6 \%$. Abatement is always welfare enhancing if $T=50$ years, while it is almost neutral in terms of lifetime consumption equivalents even if $\mathrm{T}=100$ years. This is in sharp contrast to conventional wisdom ${ }^{15}$ and to the differing recommendations in Stern (2008) and Nordhaus (2008).

We reiterate, that the underlying debate should not be about which discount rate to use ${ }^{16}$ in evaluating alternative policies, but rather on the effect of the policies on the growth rate of the economy. The discount rate is endogenous.

It has been argued in the environmental literature that the welfare of future generations should not be valued less than that of the present generation ${ }^{17}$. In our view, inter generational discounting is an ethical issue to which economic theory provides little guidance ${ }^{18}$. In table 7 we consider a case with $\beta>1$; its conclusions are consistent with our earlier observations -- there is no striking difference between tables 3-6 and table 7 .

\footnotetext{
${ }^{15}$ See Weitzman (2007). "The biggest uncertainty of all in the economics of climate change is the uncertainty about which interest rate to use for discounting".

${ }^{16}$ There is a vast literature addressing this issue. A representative sampling includes: Arrow et al (1996), Burgess and Zerbe (2011), Dasgupta (2008), Heal (1997), Kaplow, Moyer and Weisbach(2010), Pindyck (2007), Samida and Weisbach (2007), Gollier (2009), Weitzman (1998, 2007), Weisbach and Sunstein (2008).

${ }^{17}$ This position is supported by Broome (2008), Cline (2006), Cowen (2007), Dasgupta (2008), Heal (2009), Philibert (1999), Rawls (1999), Ramsey (1931) and Sidgwick (1890) among others. See the review by Revesz and Shahabian (2011).

${ }^{18}$ In contrast, for intra generational discounting, a plausible case can be made for $\beta<1$. See Arrow (1999) or Blanchard (1985).
} 
Given that the integrated assessment models abstract from a positive feedback induced catastrophe, our analysis favors a policy of abatement as an inexpensive (in terms of lifetime consumption equivalents) insurance policy, given the present modeling perspective ${ }^{19}$.

This recommendation may be strengthened in a model that incorporates endogenous technological change and substitution between technologies that will be an inevitable consequence of relative prices changes in the factors of production.

We hasten to add that we are not taking a stand on the type of abatement investment and the conclusions of our analysis do not depend on this. It may well be the case that increased investment for $R \& D$ in abatement technology today and then the use of this more efficient technology for abatement in the future may be more effective in curtailing greenhouse emissions than with existing technology.

\section{Household Heterogeneity}

Most of the climate literature assumes a "global representative household". The reality, however, is that there is significant household heterogeneity across the globe. Large parts of the population in India, China and sub-Saharan Africa live at or near subsistence levels of consumption. This group accounts for about a third of global households, and their willingness to substitute consumption over time is arguably different from that of households in more developed economies. Lending rates for poorer households are, very likely, much higher than those implied by capital market data.

\footnotetext{
${ }^{19}$ If, as shown above, abatement is approximately welfare neutral in models that abstracts from catastrophic risk, it will be welfare enhancing if we include and price this risk. The increase in welfare arises because abatement offers the benefits of a put option that we have not included.
} 
To illustrate this, consider a preference function of the form:

$$
u\left(c_{t}, \bar{c}\right)=\frac{\left(c_{t}-\bar{c}\right)^{1-\alpha}-1}{1-\alpha}
$$

where $\bar{c}$ is the subsistence level of consumption. For these preferences the relative risk aversion is:

$$
\frac{-c_{t} u^{\prime \prime}\left(c_{t}\right)}{u^{\prime}\left(c_{t}\right)}=\frac{\alpha}{\left(1-\bar{c} / c_{t}\right)} .
$$

Rich households have consumption levels well above subsistence levels and $\bar{c} / c_{t}$ for this class of households is likely to be small and their risk aversion with be approximately equal to $\alpha$. Poor households on the other hand are likely to have consumption levels closer to subsistence levels and the household's effective (or local) risk aversion becomes very large. For example, if $\alpha=2$ and $\bar{c} / c_{t} \approx 0.9$ then the effective risk aversion of these households $\approx 20$ !

How does one deal with household heterogeneity ${ }^{20}$ ? Unfortunately, as is well known, a social welfare function cannot be constructed in general if household preferences are heterogeneous. If the heterogeneous households have preferences that satisfy the conditions for aggregation ${ }^{21}$, then a representative agent can be constructed in a manner that is independent of the underlying heterogeneous agent economy's initial wealth distribution. Although aggregation permits the use of the representative agent for welfare comparisons, it substantially narrows the choice of utility functions. While the CRRA preferences

${ }^{20}$ See the recent working paper by Hassler and Kursell (2012).

${ }^{21}$ Households need to have common homothetic preferences. See Acemoglu (2008) chapter 5. 
considered in this paper satisfy the conditions for aggregation, Epstein-Zin preferences do not ${ }^{22}$. Any welfare analysis using the later preference class is effectively based on the preferences of a "global dictator". Even if preferences are of the CRRA form there is no general closed form representation that relates the heterogeneity in $\alpha$ at the household level to the curvature of the representative agent.

Economists can evaluate the impact of a policy on the welfare of each heterogeneous class of agents. Weighing the interests of different classes is an ethical issue and in general is outside the scope of economics.

\section{Conclusion}

This paper illustrates that even in a homogenous agent economy, using social discount rates for evaluating alternative abatement policies on the basis of its effects on asset valuation may not be welfare enhancing when these policies affect the growth rate of consumption.

We show that the class of abatement polices considered in the integrated assessment literature are robust with respect to the choice of a discount factor if lifetime consumption equivalents are used as a metric.

We argue against a global welfare function in the presence of significant global household heterogeneity. While economic analysis is a useful tool for evaluating different policies for a homogenous class of households, inter household comparisons are an ethical issue.

\footnotetext{
${ }^{22}$ Epstein and Zin (1991).
} 


\section{References}

Acemoglu D. Introduction to Modern Economic Growth. Princeton University Press Princeton, NJ. (2008)

Ackerman F, DeCanio S. J, Howarth R. B. and Sheeran K. Limitations of Integrated Assessment Models of Climate Change. Climatic Change 95 (2009): $297-315$

Ahlroth S. Valuation of Environmental Impacts and its Use in Environmental Systems Analysis Tools. Doctoral Dissertation, Royal Institute of Technology, Stockholm (2009).

Arrow K.J, Cline W.R, Maler K.G, Munasinghe M, Squitieri R. and Stiglitz J.E. Intertemporal Equity, Discounting, and Economic Efficiency. Climate Change 1995: Economic and Social Dimensions of Climate Change, James P. Bruce, Hoesung Lee and Erik F. Haites, Eds., Cambridge University Press 1996.

Arrow K.J. Discounting, Morality, and Gaming. Discounting and Intergenerational Equity, Paul R. Portney \& John P. Weyant eds., RFF Press Washington 1999.

Becker G.S. and Barro R.J. A Reformulation of the Economic Theory of Fertility. Quarterly Journal of Economics 103(1988): 1-25

Beckerman W. \& Hepburn C.J. Ethics of the Discount Rate in the Stern Review on the Economics of Climate Change. World Economics 8 (2007):187-208.

Blanchard O. J. Debt, Deficits, and Finite Horizons, Journal of Political Economy, 93(2)(1985): 223-247.

Brock, W. Asset Pricing in a Production Economy, in: The Economies of Information and Uncertainty, ed. by J.J. McCall, Chicago, University of Chicago Press (1982):165-192

Broome J. The Ethics of Climate Change: Pay Now or Pay More Later? Scientific American. May (2008): 69 -73

Burgess D.F. and Zerbe R.O. Appropriate Discounting for Benefit-Cost Analysis. Journal of Benefit-Cost Analysis 2 (2011): 1-43 
Cowen T. Caring About the Distant Future: Why it Matters and What it Means. University of Chicago Law Review 74 (2007): 5-40.

Cline W.R. Meeting the Challenge of Global Warming. How To Spend $\$ 50$ Billion To Make The World A Better Place. Cambridge University Press. (2006).

Dasgupta, P. Discounting Climate Change. Journal of Risk $\mathcal{E}$ Uncertainty 37 (2008): $141-169$.

DeCanio S.J. The Political Economy Of Global Carbon Emissions Reductions Ecological Economics 68 (2009): 915-924.

DeCanio S.J. and Fremstad A. Economic Feasibility of the Path to Zero Net Carbon Emissions. Energy Policy 39 (2011): 1144-1153.

Donaldson J.B and Mehra R. Comparative dynamics of an equilibrium intertemporal asset pricing model. Review of Economic Studies 51 (1984): 491 508.

Epstein L.G and Zin S.E. Substitution, Risk Aversion, and the Temporal Behavior of Consumption and Asset Returns: An Empirical Analysis. Journal of Political Economy 99 (1991): 263 - 286.

Gollier C. Should we Discount the Far-Distant Future at its Lowest Possible Rate?, Economics - The Open-Access, Open-Assessment E-Journal, Kiel Institute for the World Economy, vol. 3(25) (2009) 1-14.

Hanewinkel M, Cullmann D.A, Schelhaas M-J, Nabuurs G-J and Zimmermann N.E. Climate Change May Cause Severe Loss in the Economic Value of European Forest Land. Nature Climatic Change 3 (2013) 203 - 207.

Hassler J. and Kursell P. Economics and Climate Change: Integrated Assessment in a Multi-Region World. Working Paper 2012.

Heal G. The Economics of Climate Change: A Post-Stern Perspective. Climatic Change 96 (2009) $275-297$.

Howarth, R.B. Discounting and Uncertainty in Climate Change Policy Analysis. Land Economics 79 (2003):369-381 
Jensen M.C and Long J.B. Corporate Investment under Uncertainty and Pareto Optimality in the Capital Markets The Bell Journal of Economics and Management Science, Vol. 3, No. 1 (Spring, 1972), pp. 151-174

Kaplow L. Discounting Dollars, Discounting Lives: Intergenerational Distributive Justice and Efficiency. The University of Chicago Law Review 74 (2006) 79 - 118.

Kaplow L, Moyer E. \& Weisbach D.A. The Social Evaluation of Intergenerational Policies and its Application to Integrated Assessment Models of Climate Change. The B.E. Journal of Economic Analysis \& Policy 10 (2010)

Lucas, Jr., R. E. Asset Prices in an Exchange Economy. Econometrica 46 (1978): $1429-1445$.

Lucas, Jr., R. E. Models of Business Cycles. Yrjo Jahnsson Lectures, Basil Blackwell, Oxford 1987.

Mehra R. On the Existence and Representation of Equilibrium in an Economy With Growth and Nonstationary Consumption. International Economic Review 29 (1988): 131-35.

Mehra R. Consumption-Based Asset Pricing Models. Annual Review of Financial Economics 4(2012): 385-409.

Mehra R. and Prescott E.C. The Equity Premium: A Puzzle. Journal of Monetary Economics 15 (1985): 145-161.

Mehra R. and E. C. Prescott (2008), The Equity Premium: ABCs In Handbook of Investments: The Handbook of the Equity Risk Premium. (R. Mehra, ed.)

Elsevier, Amsterdam.

Merton R.C and Subrahmanyam M.G. The Optimality of a Competitive Stock Market The Bell Journal of Economics and Management Science, Vol. 5, No. 1 (Spring, 1974), pp. 145170

Nordhaus W. A Question Of Balance: Weighing the Options on Global Warming Policies. Yale University Press, New Haven (2008).

Philibert C. The Economics of Climate Change and the Theory of Discounting. Energy Policy 27 (1999): 913-927. 
Prescott E.C. \& Mehra R. Recursive Competitive Equilibrium: The Case of Homogeneous Households. Econometrica 48(1980): 1365 -1379.

Pindyck R.S. Uncertainty in Environmental Economics. Review of Environmental Economics \&3 Policy 1(2007): 45-65.

Pindyck R.S. Modeling the Impact of Warming in Climate Change Economics, Chapter 2 in The Economics of Climate Change, University of Chicago Press, 2011.

Pindyck R.S. Uncertain Outcomes and Climate Change Policy, Journal of Environmental Economics and Management, 63 (2012) 289-303

Revesz R.L. \& Shahabian M.R. Climate Change and Future Generations Southern California Law Review 84(2011): 1097-1163.

Ramsey F.P. A mathematical theory of saving. Economic Journal 38 (1928): 543-559.

Ramsey F.P. Truth and Probability. The Foundations of Mathematics and Other Logical Essays (1931): 156-198.

Rawls J. A Theory Of Justice. Harvard University Press. 1999.

Samida D. and Weisbach D.A. Paretian Intergenerational Discounting. University of Chicago Law Review. 74(1) (2007): 145-170

Sidgwick H. The Method Of Ethics. Oxford University.1890

Stern N, et al., The Economics of Climate Change: The Stern Review. Cambridge University Press, New York (2007).

Stern N. The Economics of Climate Change. American Economic Review 98(2) (2008): 1-37.

Tol, R.S.J. The damage costs of climate change - a note on tangibles and intangibles, applied to DICE. Energy Policy 22(1994): 436-438.

Weisbach D.A. and C.R. Sunstein, Climate Change and Discounting the Future: A Guide for the Perplexed. Yale Law $\& 3$ Policy Review 27(2008)

Weitzman M.L. A review of the Stern Review on the Economics of Climate 
Change. Journal of Economic Literature 45 (2007): 703 - 724.

Weitzman M.L. Why the Far-Distant Future Should be Discounted at the Lowest Possible Rate. Journal of Environmental Economics and Management 36 (1998): $201-208$.

Weitzman, M.L. On modeling and interpreting the economics of catastrophic climate change. Rev Econ Stat 91 (2009): 1-19 